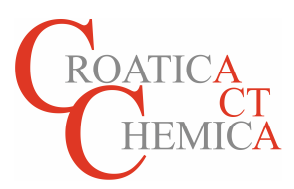

\title{
Celebrating my Ph.D. Thesis Mentor Birthday
}

\author{
On the occasion of the $80^{\text {th }}$ Anniversary of Prof. Dr. Nenad Trinajstic \\ by Predrag-Peter llich \\ New York City, NY, U.S.A.
}

$\mathbf{M}$ EMORIES fade but I still remember that sunny September day about 40 years ago. My host - a tall, athletic, and darkly handsome man, about a decade my senior - took me on a leisurely yet purposeful walk through the sprawling complex of the R. Bošković Institute(RBI), while outlining several different areas of research the members of the Theoretical Chemistry Group at RBI were engaged in.

The invitation for this visit came from my host, Prof. Dr. Nenad Trinajstić, the Head of the Group, as a response to my unsolicited letter inquiring about the possibilities to do a doctoral thesis in his group. I was charmed by Dr. Trinajstićs easygoing tone and impressed by the succinct way of presenting several theoretical chemistry topics; and yes, I was also familiar with the stellar research output of his Group, in particular in chemical graph theory.

The pace of our walk through the green fields of RBI, as well as the intensity of Dr. Trinajstić's presentation were turned high, as I was becoming more aware of his unspoken question about my intentions. I was very much interested in tackling some of the intellectual challenges Dr. Trinajstić was outlining, yet fully committing myself was a hard decision for me to make at the moment. I had to separate from my young family for several years and take a severe pay cut to my already small salary at the University of Sarajevo, where I held a junior faculty position in the Department of Physical Chemistry, and where I also had to face the strongly unfavorable view of the people who ventured to do their doctoral theses outside of their institutions. Nonetheless I made a leap: "Yes" - I said to Dr. Trinajstić "I would very much like to come to Zagreb and have you mentor me in my doctoral work."
Being a man of action, Nenad took me right away to his office in the Department of Physical Chemistry, situated in the VI wing of RBI. There, he pointed to an empty desk and located an unoccupied chair to help me with the move. Only later, a year or two into my tenure in the Group, did I fully realize the privilege I was endowed at that moment as that particular location was coveted by quite a few aspiring graduate students.

Nenad suggested that I look into certain problems related to the concepts and applications of Topological Resonance Energy, TRE; a topic which had originated in the Group and launched Nenad and few other members of the Group into the front echelons of theoretical chemistry in the late 1970s. He then handed me a few reprints and a recent Ph.D. thesis in that general area, and - that was it. Never again did Nenad tell me "what to actually do for my thesis". Yet I always had barrier-free access to him and his immediate and full attention. My questions to him were never left without advice or a suggestion. This hands-off style suited me just fine and I soon established a foothold and was progressing with my own research in this area.

Throughout these years my rapport with Nenad remained the same since the time it was established during our first encounter on that September afternoon; cordial, engaged, professional, and always intense. "Mr. Ilich," - he would sometimes tease me - "I suspect your life must significantly pick up in tempo each time you cross the Bosnian border and come to RBI!"

I also vividly remember a moment when he demonstrated a remarkable ability to turn a potentially contentious situation into a positive one. Early into my tenure in the Group, he asked me to listen carefully and comment on 
the joint manuscript he was working on. After a few minutes into his reading I made a critical remark; a couple of minutes later I made another one. At the end of his patient reading (while inserting marks in the manuscript whenever I uttered a comment) I suddenly became aware of the fact that I had pretty much decimated his manuscript. I, a novice graduate student, was harshly criticizing a wellestablished and highly prominent professor in his own area of research! For a moment I almost froze, unsure of what his reaction would be and how this whole episode would weigh on my future standing in his group. Such behavior would have been inconceivable in the academic milieu of the University of Sarajevo, from where I came. But what did Nenad do? "Good, Mr. Ilich," - he said - "good. You know what," - he continued tidying up the sheets of the manuscript and handing this sheaf to me, - "why don't you take this manuscript from this point on and finish it the way you deem more appropriate". In typical "Trina-style" character he added, semi-seriously, "I give you a week's time."

I was amazed then and I am even more amazed now, after many years, and after numerous interactions with colleagues in academia: at that moment Nenad displayed professional and managerial qualities that I have rarely witnessed ever again.
Fast-forward three years from that informal interview on the sunny September afternoon, and I had my Ph.D. thesis completed and a dozen new papers, either already published or in preparation. This was one of the most productive and intellectually satisfying periods of my life. True, the intense work and long hours I invested brought results, but it was the deeply engaged yet hands-off interaction and constant learning from Nenad that brought me from the complete obscurity of mid-Balkan academia to the threshold of worldly science.

Soon after I completed my work and obtained a Ph.D. from the University of Zagreb, Nenad helped me connect with an academic in the U.S. who extended an offer to join his research group. Although my subsequent work eventually led me away from chemical graph theory and my work at RBI, I often find myself thinking about those times. I have never met anyone like Nenad - someone as easygoing yet consistent and punctual in style and substance, intense yet sufficiently relaxed and pleasant, with a keen ability to delegate. Throughout my life I can think of only two people with the gift to accept, understand, and entrust their collaborators with authority and command: my father and Nenad Trinajstić.

I am deeply honored to salute my teacher and mentor, Prof. Dr. Nenad Trinajstić, on his $80^{\text {th }}$ Birthday. 